\title{
Chapter - Making meaning from Multimodality: Embodied communication in a business pitch setting
}

\author{
Rowena Viney \\ University College London \\ r.viney@ucl.ac.uk
}

Jean Clarke

Leeds University Business School

jsc@lubs.leeds.ac.uk

Joep Cornelissen

Rotterdam School of Management

cornelissen@rsm.nl

\section{Introduction}

A multimodal research agenda is gaining traction in organizational research;

multimodality is the theory and understanding that multiple modes of communication outside of speech and text have the potential to convey meaning (Iedema, 2007; Jones \& LeBaron, 2002; Kress \& van Leeuwen, 2001; Streeck, Goodwin \& LeBaron 2011). There is an increasing realisation that the visual, material and embodied modes of meaning-making pervade organizations and understanding these non-verbal modes of meaning creation could provide opportunities for new and interesting theoretical, empirical and methodological 
insights (Bell and Davison, 2013; Jancsary, Höllerer and Meyer, 2015). Multimodality emphasises that 'language' is just one of many resources for making meaning and that "all such resources available in one social group and its cultures at a particular moment ought to be considered as constituting one coherent domain, an integral field of nevertheless distinct resources for making meaning; all equal, potentially, in their capacity to contribute meaning to a complex semiotic entity, a text or text-like entity." (Kress, 2011:38). Within a multimodal perspective speech and text are not necessarily seen as the dominant mode of communication and are ideally not examined in isolation but as one mode of communication among many others (visual, spoken, gestural, written, three-dimensional etc.) that also potentially interact and align to generate meaning (Philips et al, 2004).

Despite this increasing interest in multimodality and its relationships to organizations and management, there remains a lack of work which empirically investigates multimodality in the context of organizations. This may be due to the significant challenges presented to researchers interested in investigating multimodality, namely the lack of multi-modal "literacy" among organizational researchers (Jancsary et al. 2015). We remain unskilled in terms of "reading", understanding and analysing multi-modal data. In particular, it is often necessary to transform multimodal data into easily accessible, text-based material so that it can be coded and reported on, which often leads to a loss of some of its original multimodal richness (Plowman \& Stephen, 2008). It is often not fully possible to articulate through language a complete sense of the bodily and interactional richness and complexity of multimodal data and all that we find interesting about this data. Without proper multimodal analytical protocols these preverbal, visceral hunches can often "remain at the level of vague suspicion and intuitive response" (Iedema, 2001: 201). There is, in other words, a need to develop the multimodal 'literacy' of researchers to ensure that multimodal data is represented 
and analysed in such a way that their contextual richness is being maintained whilst at the same time allowing for systematic analyses and theory development.

Our aim in this chapter is to give an empirical example of how multimodality can be examined in the context of entrepreneurship. Within the domain of entrepreneurship, an emerging line of inquiry focuses on how through both verbal and non-verbal communication and behavioural displays entrepreneurs may be able to convince investors to provide resources and investment (Baron and Markman, 2003;Chen, 2009; Clarke, 2011; Cornelissen \& Clarke, 2010). In this chapter we focus specifically on entrepreneurs' use of gesture when pitching for investment at organized pitch events. We focus on gesture as an element of multi-modal meaning-making which forms a central mode of human communication alongside speech. As Kendon (1983: 27) for example suggests, "gesticulation arises as an integral part of an individual's communicative effort and....has a direct role to play in this process" (italics in the original). Gesticulations (spontaneous movements of hands and arms that co-occur with speech), are one type of body movement that are thought to play an integral role in the process of communication (Alibali, Heath \& Myers, 2001). Gestures convey information complementary to speech as the mimetic and analogue format of gestures (in the form of shapes, sizes, spatial relationships) can lead to different representations of ideas compared to the more discrete and categorical format underlying grammar and speech (cf. Cornelissen et al., 2012). Thus, when gestures accompany speech, they may enable speakers to express thoughts that may otherwise not easily fit into the categorical system that their language offers (Goldin-Meadow \& McNeill, 1999).

In demonstrating one way of examining multimodality in an entrepreneurship context, this chapter considers the utility of paying attention to non-verbal data by unpacking some of the embodied practices of competent entrepreneurs. The remainder of the chapter is structured as follows. We first introduce the setting of entrepreneurship. We then describe the 
role of gesture as part of multi-modal analysis. We then discuss specific empirical work that features in our analysis. We conclude the chapter by discussing the insights afforded by gesture analysis and the contributions that this type of multi-modal analysis makes to our understanding of entrepreneurship and more widely organizational and management research. We argue that directing attention to multimodal meaning-making complements and extends research that focuses on language alone and that the potential contribution of multimodal research in organization and management research is substantial.

\section{The multimodal meaning-making of entrepreneurs}

The acquisition of resources and capital is a critical step for many entrepreneurs, which triggers the question of how entrepreneurs persuade potential investors to support their venture? Entrepreneurs generally speaking face significant problems in convincing investors of their ventures due to the 'liability of newness' (Stinchcombe, 1965) associated with their ideas, with often little in the way of a track record, obvious asset value or profitability in sight (Brush et al., 2001; Cassar, 2004; Mason \& Harrison, 2000). In this context, how entrepreneurs communicate about their ventures may be crucial to secure investment that allows them to further develop their ventures and potentially bring the business to a stable level of growth (Bird \& Schjoedt, 2009). Investment pitching events offer an opportunity for entrepreneurs to communicate their ideas and are generally seen as critical in that a successful "performance" is essential in order to gain support and resources from investors (Cornelissen \& Clarke, 2010).

There has been increasing suggestions in the recent entrepreneurship literature that that the non-verbal devices used by entrepreneurs are very important for entrepreneurial performances. Clarke (2011) demonstrates the importance of visual symbols (setting, props, dress and emotional expressiveness) illustrating how entrepreneurs use a range of visual symbols during interactions with stakeholders in order to increase low levels of legitimacy. 
Baron and Markman (2003), highlight the importance of what they refer to as 'social competence' in engaging others in the entrepreneurial venture. The idea of social competence goes beyond ideas of persuasion through linguistic domains, as it 'encompass the ability to correctly gauge the current moods or emotions of others, proficiency in inducing positive reactions in others by enhancing one's own appearance and image effectiveness in persuasion' (Vecchio, 2003, p. 318). Mason and Harrison (2000) similarly found that if entrepreneurs did not 'sell' or persuade Business Angels of the utility of their product through effective use of language, display, and artefacts, they were unlikely to secure the investment. Chen et al. (2009) also examined the importance of entrepreneurs expressing passion during interactions with investors, potential employees, and major customers. They define passion as energetic body movements, rich body language, and animated facial expression.

Building on this stream of research we aim to examine the role embodied communication plays in the context of entrepreneurship. In multimodal communication the underlying assumption is that multiple modes of meaning-making (gestures, gaze, bodily position, facial expressions) are used outside and alongside language in interpersonal communication (Kress \& van Leeuwen, 2006). Drawing on this perspective, we start from the position that when communicating individuals naturally move their bodies when they speak and these movements are not accidental, but are often tightly coupled to the communicative messages speakers wish to convey (Kaschak, Madden, Therriault, Yaxley, Aveyard, Blanchard \& Zwaan, 2005). As Goodwin (1981: 125) noted, “emergent displays...integrate the bodies of the participants into the production of talk, and are important constitutive features of the conversation". Listeners take notice of these movements and infer different things about speakers and their messages as a result of what they see (Clark, 1996; Glenberg \& Kaschak, 2002). 
The development of understanding between individuals is then fundamentally connected with the actions that their bodies perform (Semin \& Cacioppo, 2008; Richardson, Spivey, Barsalou \& McRaek, 2003). The literature suggests that hand gestures (naturally occurring gesticulations that tend to co-occur with speech), are centrally involved in language processing and communication as they convey substantive information (Goldin-Meadow, 1999; Leander, 2002; Loring, Meader, Allison \& Wright, 2000). Gestures complement speech as the mimetic and analogue format of gestures (in the form of shapes, sizes, spatial relationships) may lead to different representations of ideas compared to the more discrete and categorical format underlying grammar and speech (cf. Cornelissen et al., 2012). Thus, when gestures accompany speech, they may enable speakers to express thoughts that may otherwise not easily fit into the categorical system that their language offers (Goldin-Meadow \& McNeill, 1999) and allow listeners to infer speaker intentions and to form understanding.

While there has been little work examining the importance of gesture in organizational contexts, in other domains the importance of gesture in terms of aiding communication has been well established. For example, in the context of politics, studies of politicians demonstrate that they use gestures frequently and in strategic and pragmatic ways to persuade listeners of a point that they are trying to make (Kendon, 2004; Streeck, 2007). Argentin et al. (1990), for example, asked university students to assess the persuasiveness of a politician depending on whether he delivered the same message with (or without) hand gestures. The politician was perceived as more persuasive when he used many ideational or metaphoric gestures and a reasonable amount of speech marking or rhythmic gestures. More recently, Maricchiolo et al. (2009) established in an experiment with students that a speaker trying to persuade students of the proposal to increase university fees was judged as generally more competent, composed and effective in her communication style when she used gestures (as opposed to no gestures) and ideational gestures in particular. Building on the importance 
that gesture-related information has been shown to have in these disparate contexts, we examine the role gesture plays in communication in the context of entrepreneurship. Below we describe our research context and data in more detail.

\section{Collecting Multimodal Data}

In order to examine the multimodality in the context of entrepreneurship we employed a video-based method that allowed us to gather both linguistic and non-verbal communication. Video recording is one of the primary media that allow researchers to capture such multimodality in action. Through video, researchers can for example track facial expressions and gestures, the bodily use of artefacts, or how individual actors interact with their environment, making it an ideal method for a range of research objectives related to multimodal understanding. As Kress (2011: 253) argues "the use of the video-recorder brought with it a vivid realization of the limits of speech as either a sufficient or a central 'means of record' of meaning made." Video-analysis allows us to examine "starkly visible 'extra-linguistic' features" and opens up new possibilities for researchers by facilitating 'multi-modal' analysis through the repeated scrutiny and frame by frame examination of the same motion/speech event in micro-level detail (Luff and Heath, 2012). We video-recorded 54 pitches of varying length that took place at Business Angel pitching events around the UK in 2013 and 2014. Following Collier and Collier's (1986: 149) advice that "good video and film records for research are ultimately the product of observation that is organized and consistent" we explored a range of issues prior to capturing the videotaped data including the optimum distance for researchers to videotape participants and the type of camera angle and view which is least distracting to participants (e.g. Collier and Collier, 1986; Prosser, 1998). These types of pitching events are routinely video-recorded so the entrepreneurs involved were quite used to the experience. 
The videos were transcribed using a variant of transcription conventions developed by Jefferson (2004). These conventions capture the details of how talk is produced, for example stress, lengthened sounds, silences and audible in- and out-breaths, (please see the appendix for the transcription key). This transcription system is designed not only to capture what was said, but also the way in which it is said which is important in this case given the focus on persuasion. The analytic approach to the data was informed by conversation analysis, a method that looks at the minute detail of naturally-occurring interactions to describe the structures of social interaction (Stivers and Sidnell, 2013). A key principle of conversation analysis is that when we talk we do particular actions and there is a wealth of research on how certain types of action are accomplished by speakers, for example complaining (Drew and Holt, 1988), assessing (Pomerantz, 1984), and requesting (Curl and Drew, 2008); nonverbal means of communication are also incorporated into analysis, for example gaze (Goodwin, 1981), hand movements (Schegloff, 1984), and laughter (Jefferson et al, 1987). A second principle is that speakers orient their talk, or actions, to the rules and structures by which interaction is organised; certain types of action relate to particular other types and in particular ways, for example an offer will be followed by an acceptance or a rejection, and always in this order - ordinarily a rejection would not come before the offer (see Schegloff (2007) for an in-depth look at how interaction is organised). A further principle holds that through talk we maintain intersubjectivity, which means that as analysts we can see how utterances are interpreted by speakers by looking at how they are treated by the speakers themselves; such detail as silences or corrections of something in the talk (technically described as repair in the conversation analysis literature) can convey to both interactants and the analyst how an utterance has been understood (see Peräkylä (2004) for more on the principles of conversation analysis). The analysis below draws on these principles and the detailed interactional findings reported in the field of conversational analysis. 
For the coding of the gestures, we drew on an established protocol from cognitive science (as in Cienki 2005, adapted from Müller 1998). The focus was on individual gesture strokes, the phase of gestural movement which displays the most distinct exertion of effort (as opposed to the preparation leading up to it or the retraction of the hand after it) (Kendon, 1980, 2004). The stroke phase also provides the most information for determining a gesture's likely primary function (its 'meaning') (McNeill, 1992: 375-376). First the shape, motion, placement, and orientation of the entrepreneur's hands in each gesture was transcribed, without sound to ensure the initial gesture coding was not influenced by the speech. Following this initial coding, this initial annotation was revisited whilst listening to the speech, which allowed us to sharpen our interpretations and highlight instances where speech and gesture synchronize and align. The gestures were then categorized into ideational gestures which depict semantic information or beat gestures which mark points of emphasis in speech but "do not present a discernible meaning" (McNeill, 1992: 80). Ideational gestures were further subdivided into gestures which refer to a physical, concrete referent based on the content of the speech or gestures which are used in an ideational metaphoric way to refer to an abstract notion in terms of a physical form or movement (Cienki, 1998; Kendon, 2004).

Unlike other types of interaction such as everyday conversations or interviews, business pitches generally do not allow for audience members to respond for the duration of the pitch, meaning that as analysts we do not have access to individual audience members' interpretations of and reactions to the talk and gesture being produced. However, business pitches, like presentations in general, are still produced for an audience and are therefore interactive. For example, Rendle-Short's (2006) analysis of academic presentations, during which audience members are usually silent and still, shows that speakers use their talk and their physical actions such as gaze and gesture to show engagement with their audience. This approach may be viewed as somewhat positivist, as the audience members' responses are not 
there to guide the analysis. Moreover, as conversation analysts systematically observe people's interactional behaviour in naturally-occurring situations in an attempt to understand social organisation, this could also be viewed as tending towards positivism (Peräkylä, 2004); however, the robust manner of examining interactional data and the comprehensive set of findings about interaction documented so far ensure that analysts do not simply impose their own interpretations onto the data.

A variety of interesting phenomena were observed in the recordings made of the pitches, one of which was the use of contrasts by entrepreneurs both verbally and in their gestures. Stills from the video recording are provided in the section below to show the arm and hand gestures used in the pitches, with descriptions of the speakers' movements included by each set of images. Key parts of the talk in relation to this analysis are shown in bold.

\section{Multimodality and Entrepreneurial Communication}

In all of the pitches in the data set the presenters describe an existing problem that their product or service will solve. They might not explicitly use the terms "problem" and "solution" or "solve", but the implication that their product or service will solve a particular problem in their particular industry is still made at some point in their pitch. This tends to be set up as a contrast, with a description of the problem being followed by the entrepreneur's solution. There can be several of these problem-solution contrasts within one pitch, which the entrepreneur can use to illustrate the various advantages of their product or service in relation to various aspects of the overarching problem. Contrasts and puzzle-solution pairs were identified as rhetorical devices used in political speeches by Heritage and Greatbatch (1986), which can be used to generate responsive applause from the audience. In the context of business pitches applause only comes at the end of the pitch, but the use of these rhetorical 
devices can still serve to gain the interest of the audience and to convince them of the point that the entrepreneurs are making.

The examples below illustrate the use of contrasts by entrepreneurs when trying to persuade potential investors to support their ventures. They present these problem-solution contrasts both verbally and physically, in order to make the concept they describe as understandable as possible.

\section{Example 1}

In this extract the speaker describes a common misconception about paying for telephone calls, followed by how his product provides a solution to this apparent problem:

\section{Event 6 - Pitch 2}

$01 \mathrm{E}:$.hh Lots of people say I don't pay for my ca:lls, (0.2) well

$02->$ you do: $=$ You just actually bundle them all upp so you still

03 actually pay for your calls.

\section{$<$ figure $1>$}
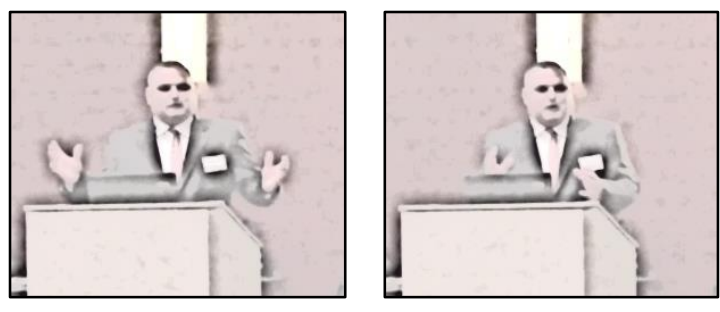

Hands reach open point on "bundle" and move together, ending movement on "up"

\section{$04 \quad(0.7)$}

05 So:: (0.2) $\uparrow$ however it's dressed up you still pay for them (.)

06 -> whereas what we can provi::de (.) is you u:se just a $\mathbf{t}^{\mathbf{h}} \underline{\mathbf{i}} \mathbf{n} \mathbf{n}$ bit

07 -> of your data ${ }^{\circ}$ package $^{\circ}(0.4)$ and all your calls are free. And

08 it doesn't matter where you are in the world. 


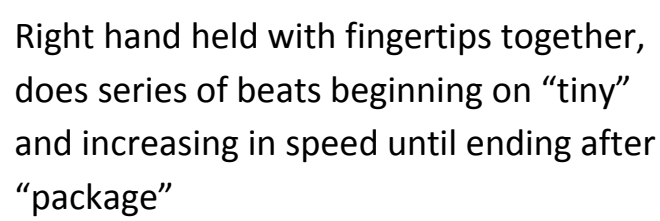

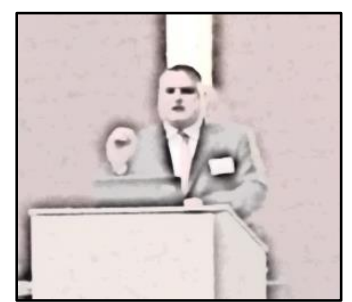

The entrepreneur begins with the statement "Lots of people say I don't pay for my ca:1ls", but then switches from the descriptor "lots of people" to the generic pronoun "you", with "well you do:", thus aggregating the group that says that they do not pay for their calls with people in general, which also includes his audience (Lerner \& Kitzinger, 2007). Shifting to this reference form means that the problem he describes is now not limited to people working in his industry but to people in general, the audience members included. He then describes how it is that people do actually pay for their calls: "You just actually bundle them all upp so you still actually pay for your calls." The term 'bundle' is used by some mobile network providers as part of the deals they advertise, so it might be recognised by the audience as an industry-related term. However, the actual meaning - to gather closely together (e.g. a bundle of hay) - suggests something more physical. As phone calls cannot be physically manipulated or bundled, this use of the word bundle is metaphoric. The presenter's gesture at this point also highlights the physical nature of the term bundle, as he acts out 'bundling up' with his hands. The speakers' hands start held out to either side of his body on "bundle"; the speaker brings them towards each other, reaching the peak position on "upp" where his hands are now in front of his body. At no point do his hands touch - at the peak of his gesture his hands are still held apart. However, throughout the movement his palms are facing each other and his hands are slightly curled inwards, which adds to the notion of 'bundling' things together. As his hands are still kept apart the impression given is of a largish 'bundle' being depicted; this seems to be reflected in his talk with "them all" being 
'bundled up'. He completes his turn with the upshot of bundling calls in this way - "you still actually pay for your calls", with the two occurrences of "actually" serving to contrast with the initial reported assertion that people don't think that they pay for their calls.

After a 0.7 second silence the presenter reformulates this upshot as “ $\uparrow \underline{h o w e v e r ~ i t ' s ~}$ dressed up you still pay for them", with a further use of metaphoric language with "dressed up". However, as he continues his talk some more metaphoric gesture can be seen. This part of his talk is immediately set up as a contrast from the content of his just prior talk, as he begins with "whereas". He then frames what is to come as an advantage of his company's service: "what we can provi::de", with stress on "we", provides the added implication of the advantage being specific to his company and not any competitor. In his description of what his business provides he explains (still using the pronoun "you", in contrast to the "we" of his company) that "you u:se just a $\mathrm{t}^{\mathrm{h}} \underline{\mathrm{i}}$ :ny bit of your data ${ }^{\circ}$ package ${ }^{\circ}(0.4)$ and all your calls are free". On " $\mathrm{t}$ hi:ny" the presenter raises his right hand to shoulder height and brings his fingertips together. He does a small beat on " $\mathrm{t}$ hịn"ny" and does a series of beats of increasing speed which end just after he produces "opackage". Although the content of his talk does not appear to contain any metaphorical language, this gesture does. Just as calls are not physically manipulatable, nor is internet or mobile data. Yet his hand position appears to show a physical size of data that they use to provide this service, enacting 'tiny'.

So in this extract we have three sets of contrasts being implied:

1. The first part of his talk sets out the problem: people think that they don't pay for their calls but it turns out that they do, so they are paying for things that they think they are not. The second part contains the solution: the service that they provide uses a small bit of data and then calls are genuinely free. 
2. In his talk he contrasts what customers pay for - a 'bundle' of calls versus a 'tiny bit of data'.

3. In his gesture, by enacting the act of 'bundling' and 'a tiny bit', he reiterates what is in his talk but also adds a further physical element - the 'bundle' he appears to be holding is large, as can be seen by the distance between his hands, whereas the 'tiny bit of data' can be held between his closed fingers in his next gesture; this pairing of gestures shows how size is an important concept in this context - a bundle of calls (big) is bad (expensive) but a tiny bit of data (small) is good (cheap).

His choice of language together with his use of gesture serve to highlight the contrast between the problem he describes and the solution his business can provide.

\section{Example 2}

Just before the start of this extract the presenter had said that he will list three advantages of the service that his business provides. This example describes the first of these advantages, to do with "turnaround times":

\section{Event 6 - Pitch 8}

$01 \mathrm{E}:$ The fir:st (.) is turnaround times.

$02(0.4)$

03 Instead of: background checks being processed by a human data

04 processor .hhh and >processed < in batches, (0.3) our:: $\underline{\text { candidate }}$

05 driven (.) online software is able to process checks (.) $\underline{\text { as }}$ and

06 when they come in (.) and produce live results. 

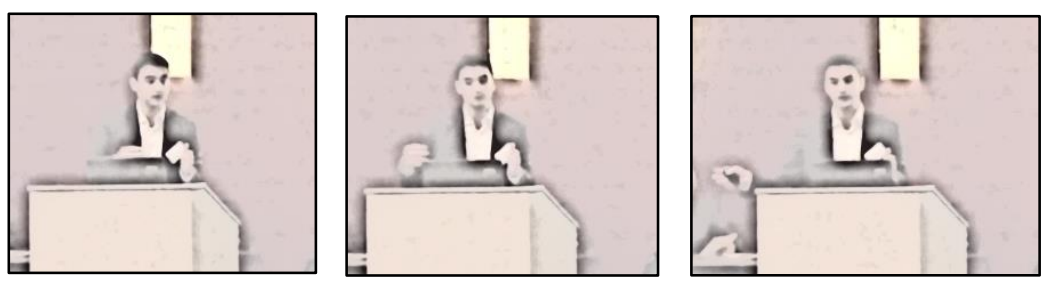

Right hand is moved from left to right, 'bouncing' three times as it moves during "processed in batches"
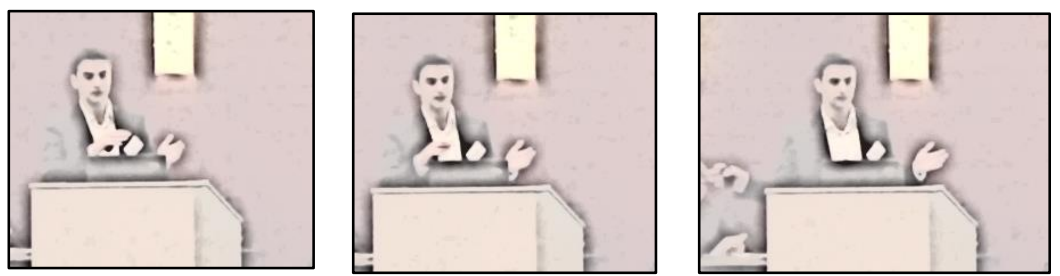

Right hand starts from furthermost left point on "checks" and moves in a smooth line from left to right during "as and when"

The presenter's first utterance describes the first advantage of the service that his business provides, to do with "turnaround times". He indicates that there will be a contrast set out in his talk by beginning with "Instead of:". The first part of the contrast sets out two elements of how current companies provide their service: firstly they use "a human data processor" to process background checks, and secondly they are ">processed $<$ in batches". The second part of the contrast sets out what the presenter's company does differently: they use "our:: candidate driven (.) online software", and process checks "as and when they come in"; he also emphasises the 'us and them' contrast by placing stress on and lengthening “our::". So using 'human data processors' and processing checks in 'batches' is set up as the problem, the undesirable way of working and getting results. This is contrasted with using software and processing checks 'as and when', which is more desirable and the solution to the problem.

The specific contrast between how background checks are processed - ">processed $<$ in batches" versus "process checks (.) as and when" - is reflected in the presenter's gesture. At ">processed<" his left hand is held at chest height close to his body. This hand remains roughly in this position. His right hand, however, beats near his left hand and then moves to the right, beating again at the right side of his body, and doing a final beat out to his right 
side. This bouncing movement appears to illustrate working in batches, with someone physically doing one batch, and then another, and then another. When describing processing checks "as and when they come in", the presenter holds his left hand slightly out to his left and moves his right hand from its start position slightly to the right of his left hand on "checks" in a smooth line during "as and when", finishing with his right hand far out to his right. The two movements - the 'bouncing' and the smooth - follow the same trajectory and end with the speaker's right hand in a very similar position. This same trajectory highlights the difference between the movements: one is halting whereas the other is smooth.

So again there are a set of contrasts in this one utterance:

1. The problem of a more time-consuming way to process checks using humans working in batches, contrasted with the solution of using software to process checks as and when with the implication that this is quicker.

2. A bumpy hand movement versus a smooth hand movement, which not only illustrates the idea of there being several batches but also implies the idea of a rough or bumpy path versus a smooth and efficient one.

\section{Example 3}

In this last extract the entrepreneur explicitly indicates that his company addresses a problem and has a solution: "So: (.) the $\uparrow$ problem we solv:e for big <agencies> $\downarrow$ is ...":

\section{Event 6 - Pitch 11}

$01 \mathrm{E}$ : So: (.) the $\uparrow$ problem we solv:e for big $<$ agencies $>\downarrow$ is when they

02 have m:ajor clients the (bit-) (0.2) m:edia agencies I mean $(0.3)$

03 when they hav:e \#a a a\# big client $\downarrow$ in the $<$ like of $>$.hhhh 
04 ((company)) or:: er:: (0.3) yẹ::s (0.5) or: er ((company)) (.)

05 -> <they want to> (0.2) run: campaigns acr:0:::ss the board. bu:t

06 -> they need to use (0.6) a platform for web a platform for mobile

07 -> a platfor:m for digital out of home.

<figure 4>
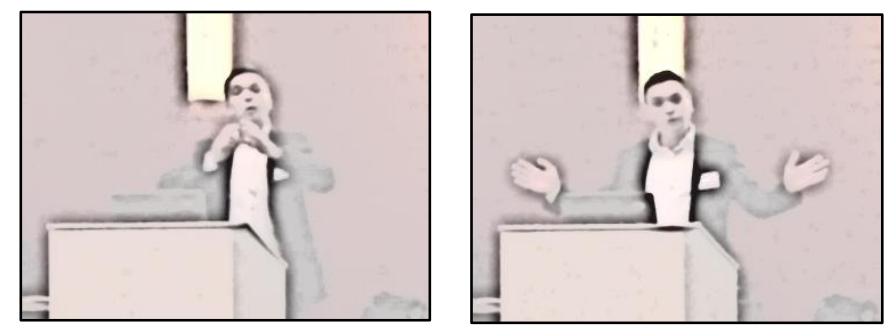

Hands together at start of "across" and at far apart end point at end of

"across"
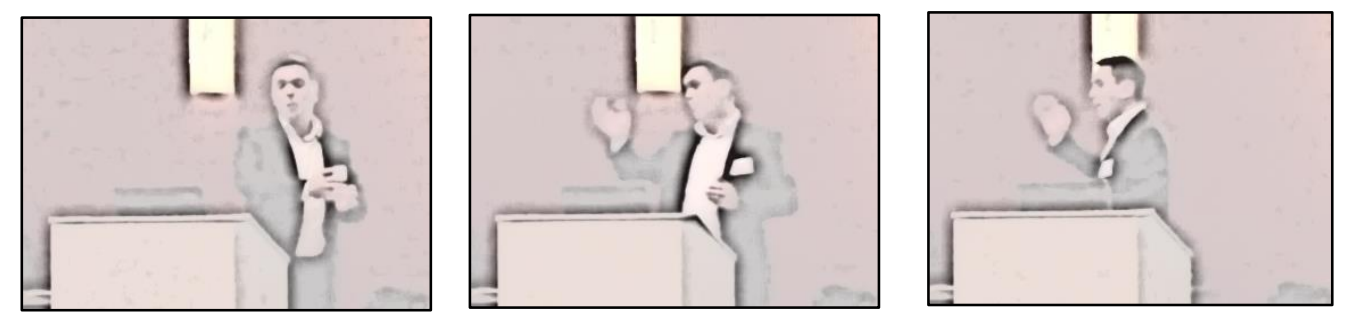

Right hand does three beats as arm moves left and body rotates left, on the three repetitions of "platform"

$08 \quad(0.2)$

09 -> U::S what we did (0.2) is: centralise (0.2) every inventory: $(0.3)$

10 in:side one single platform.

$<$ figure 5 $>$
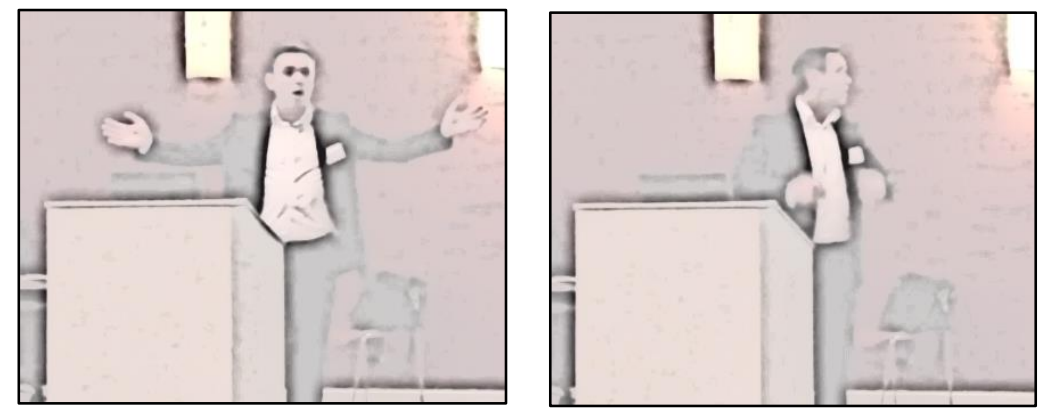

Arms wide open on "us", brought together by "did", after which speaker moves straight into deictic gesture towards slide from "is centralise" 
The entrepreneur begins by saying that the problem he is describing affects "big agencies", which he then specifies as media agencies by repairing his talk (Schegloff, Jefferson \& Sacks, 1977), and he goes on to describe that the problem is specific to a particular need that these "big agencies" have: having big clients who want to run campaigns "across the board", but in order to do so "they need to use (0.6) a platform for web a platform for mobile a platfor:m for digital out of home". The implication is that the problem is not that agencies want to go "across the board" but that in doing so they have to do three separate thing by using three different platforms. After a 0.2 second gap he contrasts this in the next part of his talk: rather than going "across the board" using three platforms that each address a different area, his company has 'centralised' everything within just one platform. He also emphasises the contrast between the existing problem and his company's solution by starting his utterance with "U::s" which is both stretched and stressed, and then following with what they did to solve the problem.

The language that he uses to describe the problem and solution is metaphoric. So although "platform" is a technical term used in the realms of software/technology, and platforms in this context are not things that are physically manipulatable, the term still has implications of the physical. Both "across the board" and "platform" conjure up images of physical objects: platforms can be physical levels/areas where you can walk on or put things on, and running something across a board suggests moving something physically over a flat space with a specific determined area. The gesture that he uses in conjunction with his talk contributes to this sense of the physical. At the start of "across" his hands are held together at neck level with his elbows out to the sides but as he produces this word he opens both his arms out wide to his sides. This also suggests a wide breadth of area to cover when running campaigns. This breadth is further suggested in his gesture when listing the three platforms 
that need to be used; his right hand moves from right to left in three stages, with a beat on the production of each instance of "platform".

During the contrast part of his talk, in which he provides the solution to the problem, he begins his utterance with his arms wide open on "Us", and brings them towards each other by the time he completes "did". This movement together appears to visually depict "centralise", and the similar arm shape to his prior utterance continues the theme of breadth and reducing this breadth.

So the entrepreneur's utterance again encompasses a set of contrasts:

1. He describes the problem, that there is a wide breadth of different platforms to run across, followed by the solution, that his company's service means that customers only need to use one platform, which is therefore simpler and quicker

2. The verbs that he uses are contrastive: "run across the board" versus "centralise every inventory"

3. He contrasts amounts, with the problem involving using three platforms and the solution using only one platform

4. The presenter's gesture shape is similar throughout, however his initial movement of his arms opening out contrasts with his arms then closing in

5. The first part of the contrast includes three movements: three beats on three repetitions of "platform"; however, the second part has just one movement, which occurs just before he produces "centralise"

These individual elements all serve to highlight the differences between the two parts of the contrast.

Setting up a problem-solution contrast serves two purposes in the pitches here. Firstly, by describing an existing problem the entrepreneur shows that there is a space in their 
particular market for them to operate in, thereby justifying their existence in the market. By providing the solution to this problem, in the form of what their business offers, they also (or so they hope) show that their product or service is appropriate to fill the gap in the market that they identified as the problem, thereby justifying their product or service as well. Secondly, in describing their solution to the problem they are also explaining to their audience something about their product by providing information about the service that they offer. So the whole problem-solution contrast provides the entrepreneurs' audience with both information about their product or service, and a justification for having developed the product or service the in the first place.

\section{Conclusion}

This chapter aims to illustrate an approach that places multimodality at the heart of our analyses of organizational conduct; we give one example of the importance of non-verbal resources in the context of entrepreneurship where entrepreneurs seek to persuade investors to fund their venture. The chapter centres on the data from a video-based study of entrepreneur's pitches for investment at an organised pitch event in the UK. In particular it considers how entrepreneurs employ gestures alongside speech to communicate their venture most effectively. Drawing on data collected as part of a larger study on entrepreneurship, we highlight the role of gesture in entrepreneurship, and multi-modal research more generally. In doing so, we show some of the informal and tacit practices that underpin the production of a persuasive message. One notable practice is the use of metaphor in both the entrepreneur's talk and their gesture is also a way to explain something quite abstract that the audience might not have much knowledge about. By using metaphor both verbally and in their arm and hand movements, the entrepreneurs in the examples given here 'give sense' about their products and services to the potential investors in the audience, by adding commonly known 
attributes to the more abstract details of their products: a bundle of calls is visually represented as something being physically bundled together, work done in batches is visually depicted as a bumpy process compared to work done 'as and when' which is visually depicted as smooth, and using three platforms for a campaign is visually depicted as wide compared to using a centralised platform which is depicted as small. The analyses here shows how those creating new ventures have to rely upon their own speech and visual presentation (Baron and Brush, 1999), including their gestures, to naturalize their venture and to provide a compelling and convincing rationale that accounts for its existence and appeals to others for their support. Speakers have a range of resources to use in their interactions: the words they use, the gestures they make, and the metaphor that can be in both the verbal and the physical. Using a multi-modal lens we can look beyond just the spoken element of this kind of data to see how visual elements contribute to what speakers are communicating to their audiences.

\section{Appendix}

\section{Transcription symbols}

\begin{tabular}{|l|l|}
\hline$\underline{\text { word }}$ & Underlining indicates stressed or emphasised sounds \\
\hline wor:d & Colons indicate lengthened sounds (more ':' indicate a longer stretch) \\
\hline${ }^{\circ}$ word $^{\circ}$ & Quieter than the surrounding talk \\
\hline$>$ word $<$ & Faster than the surrounding talk \\
\hline$<$ word $>$ & Slower than the surrounding talk \\
\hline$\uparrow$ & Raised pitch within an utterance \\
\hline$\downarrow$ & Lowered pitch within an utterance \\
\hline
\end{tabular}




\begin{tabular}{|l|l|}
\hline$(0.2)$ & Silence, measured in tenths of a second \\
\hline$()$. & Silence of less than one tenth of a second \\
\hline$\cdot$ & Lowered or final intonation at end of word/utterance \\
\hline$=$ & Continuing intonation at end of word/utterance \\
\hline word- & Utterance produced immediately after another with no interval \\
\hline.$h h$ & Cut-off of sound \\
\hline$\#$ word\# & Creaky or croaky sound \\
\hline whord & Aspiration sound within an utterance \\
\hline$(($ word $))$ & Anonymised information \\
\hline
\end{tabular}

\section{References}

Alibali, M. W., Heath, D. C. \& Myers, H. J. (2001). Effects of visibility between speaker and listener on gesture production: Some gestures are meant to be seen. Journal of Memory and Language, 44(2), 169-188.

Baron, R. A. and Markman, G. D. (2003). Beyond social capital: the role of entrepreneurs' social competence in their financial success. Journal of Business Venturing, 18, 41-60.

Bell, E. and Davison, J. (2013). Visual management studies: Empirical and theoretical approaches. International Journal of Management Reviews, 15(2), 167-184.

Brush, C. G., Greene P. G. and Hart, M. M. (2001). From initial idea to unique advantage: The entrepreneurial challenge of constructing a resource base. Academy of Management Executive, 15(1), 64-78 
Cassar, G. (2004). The financing of business start-ups. Journal of Business Venturing, 19(2), 261-284.

Chen, X. P., Yao, X. \& Kotha, S. (2009). Entrepreneur passion and preparedness in business plan presentations: A persuasion analysis of venture capitalists' funding decisions. The Academy of Management Journal, 52(1), 199-214.

Cienki, A. (1998). Metaphoric gestures and some of their relations to verbal metaphoric expressions. In J. P. Koenig (Ed.) Discourse and Cognition: Bridging the Gap. Stanford, CA, 189-204.

Cienki. A. (2005). Image schemas and gesture. In From Perception to Meaning: Image Schemas in Cognitive Linguistics, B. Hampe (Ed.). Berlin: Mouton de Gruyter, 421442.

Clark, A. (1996). Being There: Putting Brain, Body and World Together. Cambridge MA: MIT Press.

Clarke, J. (2011), Revitalizing Entrepreneurship: How visual symbols are used in entrepreneurial performances. Journal of Management Studies, 48(6), 1365-1391.

Collier, J. and Collier, M. (1986). Visual Anthropology: Photography as a Research Method. Albuquerque: University of New Mexico Press.

Cornelissen, J. \& Clarke, J. (2010), Imagining and rationalizing opportunities: Inductive reasoning, and the creation and justification of new ventures. Academy of Management Review, 35(4), 539-557.

Cornelissen, J. P., Clarke, J. S. \& Cienki, A. (2012) Sensegiving in entrepreneurial contexts: The use of metaphors in speech and gesture to gain and sustain support for novel business ventures. International Small Business Journal, 30(3): 213-241.

Curl, T. S. \& Drew, P. (2008) Contingency and action: a comparison of two forms of requesting. Research on Language and Social Interaction, 41(2), 129-53. 
Drew, P. \& Holt, E. (1988) Complainable matters: the use of idiomatic expressions in making complaints. Social Problems, 35, 398-417.

Glenberg, A. M. \& Kaschak, M. P. (2002). Grounding language in action. Psychonomic Bulletin and Review, 9(3), 558-565.

Goldin-Meadow S. and McNeill, D. (1999). The role of gesture and mimetic representation in making language the province of speech. Corballis, M. C. and Lea, S. (eds.) The Descent of Mind. Oxford: Oxford University Press, 155-172

Goodwin, C. (1981). Conversational Organization: Interaction between Speakers and Hearers. New York: Academic Press.

Heritage, J. \& Greatbatch, D. (1986) Generating applause: A study of rhetoric and response at party political conferences. American Journal of Sociology, 92(1), 110-157.

Iedema, R. (2001). Analysing film and television: a social semiotic account of Hospital: an Unhealthy Business. In T. Van Leeuwen, and C. Jewitt, C. Handbook of Visual Analysis. London: Sage, 183-204

Iedema, R. (2007). On the multi-modality, materiality and contingency of organization discourse. Organization Studies, 28(6), 931-946.

Jancsary, D., Hollerer, M. A. and Meyer, R. E. (2015). Critical analysis of visual and multimodal texts. In R. Wodak and M. (eds.) Critical Analysis of Visual and Multimodal Texts. London: Sage, 180-204.

Jefferson, G. (2004). Glossary of transcript symbols with an introduction. In G. Lerner (ed.). Conversation analysis: Studies from the first generation, Amsterdam: John Benjamins, $13-32$.

Jefferson, G., Sacks. H and Schegloff, E. A. (1987) Notes on laughter in the pursuit of intimacy. In G. Button and J. R. E. Lee (Eds.) Talk and Social Organization. Clevedon, England: Multilingual Matters, Ltd., 152-205. 
Jones, S. E. and LeBaron, C. D. (2002). Research on the relationship between verbal and nonverbal communication: Emerging integrations. Journal of Communication, 52(3), 499-521.

Kaschak, M. P., Madden, C. J., Therriault, D. J., Yaxley, R. H., Aveyard, M., Blanchard, A. A. and Zwaan, R. A. (2005). Perception of motion affects language processing. Cognition, 94(3), 79-89.

Kendon, A. (1983). Gesture and speech: How they interact. In Wiemann, J. M. and Harrison R.P. Nonverbal Interaction. Beverly Hills, CA: Sage Publications, 13-43.

Kendon, A. (2004). Gesture: Visible Action as Utterance. Cambridge: Cambridge University Press.

Kress, G. (2011) Partnerships in research: Multimodality and ethnography. Qualitative Research, 11(3), 239-260.

Kress, G. and Van Leeuwen, T. (2001). Multimodal Discourse: The Modes and Media of Contemporary Communication. London: Arnold.

Leander, K. (2002). Silencing in classroom interaction: Drawing and relating social space. Discourse Processes, 34, 193-235.

Lerner, G. \& Kitzinger, C. (2007) Extraction and aggregation in the repair of individual and collective self-reference. Discourse Studies, 9(4), 526-557.

Loring, D., Meador, K., Allison, J. \& Wright, J. (2000). Relationship between motion and linguistic activation using fMRI. Neurology, 54, 981-983.

Luff, P. and Heath, C. (2012). Some "technical challenges" of video analysis: social actions, objects, material realities and the problems of perspective. Qualitative Research, 12(3), $255-279$.

Mason, C. M. and Harrison, R. T. (2000). 'Investing in technology ventures: what do business angels look for at the initial screening stage?'. In Frontiers of 
Entrepreneurship Research, Proceedings of the Babson- Kauffman Entrepreneurship Research Conference

McNeill, D. (1992). Hand and Mind: What Gestures Reveal about Thought. Chicago:

University of Chicago Press.

Philips, N., Lawrence, T. B. and Hardy, C. (2004). Discourse and institutions. Academy of Management Review, 29(4), 635-652.

Plowman, L and Stephen, C. (2008). The big picture? Video and the representation of interaction. British Educational Research Journal, 34(4), 541-565.

Richardson, D. C., Spivey, M. J., Barsalou, L. W. \& McRae, K (2003). Spatial representations activated during real-time comprehension of verbs. Cognitive Science, 27(5), 767-780.

Schegloff, E. A., Jefferson, G. \& Sacks, H. (1977) The preference for self-correction in the organization of repair in conversation. Language, 53(2), 361-382.

Semin, G. R. \& Cacioppo, J. T. (2008). Grounding social cognition: Synchronization, coordination, and co-regulation. In G. R. Semin \& E. R. Smith (Eds.), Embodied Grounding: Social, Cognitive, Affective and Neuroscientific Approaches. Cambridge: Cambridge University Press, 119-147.

Stinchcombe, A. L. (1965). 'Social structure and organizations'. In March, J. G. (Ed.), Handbook of Organizations. Chicago, IL: Rand-McNally, 142-93.

Streeck, J. Goodwin C. and LeBaron, C. (2011). Embodied Interaction: Language and Body in the Material World. Cambridge: Cambridge University Press. 